\title{
COMUNICACIÓN
}

\section{SEROPREVALENCIA DEL VIRUS DE LA INFLUENZA AVIAR EN BROILERS EN LA PROVINCIA DE HUARAL, LIMA}

\author{
Luis Monasí F. ${ }^{1}$ y Eliana Icochea $\mathrm{D}^{\prime} \mathbf{A}^{2}$
}

\section{Abstrect}

\begin{abstract}
The seroprevalence of Avian Influenza antibodies was determined utilizing ELISA (KPL) technique to analyze 384 broilers collected from 36 poultry farms in Chancay (Lima, Perú) at the end of 1998 and the beginning of 1999. All the animals had suffered from light to severe respiratory processes, 10 to 15 days prior to sample collection. No antibodies against Avian Influenza Virus, serotype A/turkey/wisconsin/66/H9N2 were detected, indicating that these birds have not been exposed to this serotype. We recommend that similar Avian Influenza prevalence monitoring studies should be carried out in other areas to determine its epidemiology in Peru.
\end{abstract}

Key words: Ortomixoviridae, Avian Influenza, «Avian Pest».

Palabras clave: Ortomixoviridae, influencia aviar, «peste aviar».

La influenza aviar, es una enfermedad infecciosa ocasionada por un virus de la familia Ortomixoviridae. El curso clínico patológico de la enfermedad en aves domésticas es extremadamente variable. La infección puede ser subclínica, limitante o inducir severa enfermedad generalizada con altas tasas de morbilidad y mortalidad; todo esto depende del tipo de virus infectante, los tipos H5 y $\mathrm{H} 7$ son altamente virulentos, de alta capacidad de mutación y de gran importancia en salud pública por el papel que juegan en la evolución de nuevas cepas inclusive en humanos.

Los gastos y pérdidas económicas se pueden expresar por la alta mortalidad y baja de postura. En este sentido la Unión Nacional de Avicultores de México calculó en 49

\footnotetext{
1 Práctica privada

3 Laboratorio de Patología Aviar - FMV UNMSM. E.Mail:d170022@unmsm.edu.pe.
}

millones de dólares las pérdidas monetarias del sector avícola durante el brote de influenza aviar de alta patogenicidad producido en diciembre de 1994 y que duró hasta mayo de 1995.

En el Perú la provincia de Huaral es el principal centro de crianza de pollos de carne, con $50 \%$ de la población de cargas mensuales (ocho millones de aves). Es importante en áreas de alta producción como Huaral implementar sistemas de vigilancias epidemiológicas que permitan identificar la presencia de enfermedades virales en las parvadas. El sistema debe tener en cuenta la presencia de aves migratorias que llegan a nuestro litoral como consecuencia de cambios y fenómenos climatológicos. Por este motivo se eligió esta zona para el estudio epidemiológico del virus de Influenza Aviar.

La zona en estudio se ubica al norte de Lima y las empresas avícolas tienen ubicadas sus granjas en un área aproximada de 
$2,000 \mathrm{~km}^{2}$. El diseño de las granjas es a "galpón abierto" permitiendo el ingreso y salida de vectores como aves silvestres, perros y zorros, los que constituyen un riesgo potencial de contagio para cualquier enfermedad aviar. Además la crianza de aves de traspatio como "gallos de pelea" y principalmente patos constituyen un gran peligro ya que pueden actuar como reservorios del virus de influenza aviar.

Dada todas estas condiciones de riesgo para la zona en estudio, si se presentara un brote de influenza aviar, sería catastrófíco en términos económicos para los avicultores de la zona y del país.

El objetivo del presente trabajo fue determinar la seroprevalencia del virus de la influenza aviar en pollos broilers de la provincia de Huaral, mediante el uso de la prueba por tratarse de una zona con alta incidencia de cuadros respiratorios, compatibles indistintamente con la enfermedad de Newcastle, bronquitis infecciosa, síndrome de cabeza hinchada, influenza aviar y otros de ELISA (KPL).

Se utilizaron pollos broilers $(n=384)$ mayores de 42 días de edad. Las muestras de sangre fueron recolectadas mediante punción de la vena braquial haciéndose uso de agujas descartables de un solo uso por ave y tomadas en frascos estériles de vidrio para posteriormente obtener el suero. Todas las muestras fueron identificadas, tomándose en cuenta el tipo de explotación, lote, línea genética, nombre de la empresa, localización de la granja, región y zona geográfica a la que pertenecen.

La detección de los anticuerpos contra el virus de influenza aviar fue realizado de acuerdo al manual del kit comercial de ELISA (KPL).

Este estudio iniciado como parte de un plan integral de vigilancia epidemiológica de enfermedades exóticas indica la ausencia de aves reactores a Influenza Aviar en la zona de Huaral; sugiriendo que los broilers de crianza comercial de esta región avícola no han sido expuestas al virus de influenza aviar. Probablemente las medidas de cuarentena y vigilancia epidemiológica establecidas por el Servicio Nacional de Sanidad Animal (SENASA) en colaboración de la Facultad de Medicina Veterinaria de la UNMSM, estén contribuyendo a mantener el estatus sanitario de la industria avícola, sin embargo la vigilancia no solamente debe limitarse a poblaciones domésticas, si no también de las aves silvestres y migratorias donde debería investigar por la existencia de cepas avirulentas o de alta patogenicidad aún cuando no se han reportado brotes de esta enfermedad ocasionadas por cepas virulentas conocidas como "peste aviar" en los países limítrofes con el Perú y en América del Sur.

Se sabe que en otros estudios realizados quedó demostrado la presencia de anticuerpos contra influenza $A$ en aves reproductoras $(37.5 \%)$, pondedoras $(30 \%)$ y de carne $(36 \%)$ mediante la inhibición de la hemaglutinación y empleando como antígenos cepas de infuenza $A$ humanas; cepas A/URSS/(H1N1); A/Texas/(H2N2) y ATC/VR95/11/73 sugiriendo que estos resultados se deben al contagio de las aves por cepas humanos.

Los beneficios económicos a causa de no tener esta enfermedad son altos. Si se presentara una epizootia por el virus de baja patogenicidad, con mortalidades promedio en pollos de carne del $15 \%$; esto produciría una pérdida de aproximadamente tres millones de dólares americanos mensuales. Esta cifra ya elevada prodría incrementarse si no se toman medidas inmediatas de control y erradicación, características mutagénicas del virus para ser altamente virulentos, tal como lo ocurrido en Pennsylvania - USA (Ortiz, 1996).

La ventaja de mantenernos libres de esta enfermedad nos permite emitir certi- 
ficados zoosanitarios libres de influenza aviar, lo que implicaría poder realizar exportaciones de aves comerciales y productos avícolas en general.

Por estas razones se deben implementar barreras sanitarias, vigilancia a través de monitoreos y notificaciones, cuarentenas, educación y divulgación a los productores y personas ligadas al sector avícola (Easterday y Beard, 1984; Ortiz, 1996).

\section{Literatura Citada}

1. Easterday B.C. y C. W. Beard. 1984. Avian Influenza. In M.S. Hofstad, H.J. Barnes, B. W. Calnek, W. M. Reid., and H.W. Yoders, Diseases of Poultry. Iowa State Univ. Press., Ames. USA. 8th Ed: $482-496$.

2. Ortiz M. A. 1996. International experiences in the eradication of avian influenza. p.305-306. Proceedings of the forty-fifth. Western Poultry Disease Conference. Cancún, México. 